Navakodi Gurusamy

Jawahar Natarajan

Palaniappan Kanagasabai Palaniappan

https://doi.org/10.21278/TOF.43408

ISSN 1333-1124

eISSN 1849-1391

\title{
PARAMETER OPTIMIZATION OF THE CNC WIRE-CUT EDM PROCESS FOR MACHINING ALUMINIUM 6063-B4C METAL MATRIX COMPOSITES
}

\begin{abstract}
Summary
In the competitive manufacturing environment, conventional monolithic materials cannot compete with composite materials in the ever growing market because of their inherent limitations. Consequently, composite materials are preferred globally in major industries. $\mathrm{CNC}$ wire-cut electrical discharge machining is one of the non-traditional machining (NTM) processes, which are used to cut ferrous and non-ferrous metals with properties ranging from low hardness to high hardness and especially to cut high hardness materials and complicated profiles and shapes of all engineering and aerodynamic products. The process parameter setting is critical in the wire-cut electric discharge machining (WEDM) as it has a direct impact on performance characteristics. This paper addresses the preparation of aluminium metal matrix composites (AMMCs) and the optimization of the WEDM process parameters for machining AMMCs to improve the key performance characteristics, namely the metal removal rate (MRR), the surface roughness (SR), and the kerf width (KW). The optimization of the WEDM process parameters is multi-objective in nature. The prime objective of this study was to obtain optimal WEDM process parameters for machining AMMCs with the maximum MRR and the minimum SR and KW. The grey-based Taguchi method was applied to choose an optimal parameter combination to achieve the above said performance characteristics. AMMCs with the base metal A16063 and the reinforcement of boron carbide $\left(\mathrm{B}_{4} \mathrm{C}\right)$ in three different percentages $(3 \%, 6 \%$ and $9 \%)$ were obtained by using the stir casting method. WEDM experiments were conducted and the optimal process parameters were found to be as follows: servo voltage (SV)-26V, pulse on time (Ton)-122 $\mu \mathrm{s}$, pulse off time (Toff)$52 \mu \mathrm{s}, \mathrm{B}_{4} \mathrm{C}-6 \%$, wire feed $-3 \mathrm{~m} / \mathrm{min}$, and wire tension- $49.05 \mathrm{~N}$. The key findings from this study reveal that the MRR was increased from $35.759 \mathrm{~mm}^{3} / \mathrm{min}$ to $42.229 \mathrm{~mm}^{3} / \mathrm{min}$, the SR decreased from $4.500 \mu \mathrm{m}$ to $4.382 \mu \mathrm{m}$ and the $\mathrm{KW}$ decreased from 371 micron to 364 micron.
\end{abstract}

Key words: $\quad$ machining optimization, metal matrix composites, WEDM process, Taguchi, grey relational analysis.

\section{Introduction}

In general, monolithic materials used to manufacture aviation parts, automobile parts, marine parts, sports equipment and medical devices are fabricated by traditional machining operations such as turning, milling, drilling, grooving, or shaping. Conventional monolithic 
materials cannot compete in the ever growing market because of their inherent limitations. The properties such as strength, stiffness, toughness and density are the barriers for a wide usage of the materials under different working conditions. This leads to a decrease in efficiency and also an increase in total manufacturing cost because of the weight factor and the strength factor of the materials. To overcome these limitations, composite materials are preferred globally in major industries, Rama Rao and Padmanaban [7]. Among various types of composite materials AMMCs are used in the aerospace, automobile and defence industries, nuclear power plants, the electronics, bio-medical and sporting industries and nozzles for fluid flow. Gowri Shankar M C et al. [5] stated that AMMCs are preferred because of their properties, such as high strength-to-weight ratio, high toughness, high specific strength, good wear resistance, and low thermal expansion coefficient. AMMCs can be fabricated by using the stir casting process. [1,9] Among various aluminium alloys, aluminium 6063 is preferred for the preparation of metal matrix composites due to its superior formability characteristics, medium-to-high strength and good corrosion resistance along with low density. AMMCs are strengthened by reinforcing them with hard ceramic particles, such as $\mathrm{SiC}, \mathrm{Al}_{2} \mathrm{O}_{3}$, or $\mathrm{B}_{4} \mathrm{C}$. $\mathrm{Al}-\mathrm{B}_{4} \mathrm{C}$ composites have the potential for combining the high stiffness and hardness of $\mathrm{B}_{4} \mathrm{C}$ with the ductility of aluminium and they still reach the goal of obtaining a stiff low density material. They find their use as structural neutron absorbers, armour plate materials, and as a substrate material for computer hard disks. R. S. Rana et al. [3] stated that hardness of AMMCs increases with an increase in $\mathrm{B}_{4}$ Cpercentage. It has been observed that the increase in the $\mathrm{B}_{4} \mathrm{C}$ content of up to $7 \%$ resulted in an increase in the hardness of the composite by $18 \%$. K. Kalaiselvan et al. [6] pointed out that $\mathrm{B}_{4} \mathrm{C}$ reinforced aluminium matrix composite has gained more attraction as it can be cast by using a low cost casting method. $\mathrm{B}_{4} \mathrm{C}$ reinforced aluminium composites have a stronger interfacial bonding compared to other composites, such as $\mathrm{Al}-\mathrm{SiC}$ and $\mathrm{Al}-\mathrm{Al}_{2} \mathrm{O}_{3}$. The traditional stir casting is an attractive manufacturing processing method for making AMMCs. Stir casting offers stronger matrix particle bonding due to the stirring action of particles in the melts.

Nihat Tosun et al. [12] said that the traditional machining of AMMCs materials causes serious tool wear due to the existence of abrasive reinforcing particles and thus reduces the tool life. Hence, NTM techniques are preferred for machining new and harder materials such as metal metrics composites (MMCs), used in nuclear, missile, aerospace, automobile, tool and die industries. Among various NTM techniques, the WEDM shows a higher capability for cutting complex shapes in these materials with high precision. The process parameter setting is critical in the WEDM as it has a direct impact on performance characteristics. Chockalingam et al. [11] used the Taguchi method based on the grey relational analysis to find optimal process parameters in the WEDM. Reference voltage, Ton, Toff, fluid injection pressure mode, wire tension, and wire velocity are crucial machining process parameters which have influence on the machining performance characteristics, such as MRR, surface roughness, spark gap and dimensional deviation while processing or slicing an ingot. The number of AMMCs applications is anticipated to increase with the development of low-cost processing methods. $\mathrm{B}_{4} \mathrm{C}$ particles are found to be a superior reinforcement material than silicon carbide for a high performance metal matrix composite and are a better alternative to $\mathrm{SiC}$ and $\mathrm{Al}_{2} \mathrm{O}_{3}$ due to their high hardness, high strength, low density, good wear resistance and good chemical stability. Hence, in this study boron carbide is chosen as a reinforcement material in the aluminium matrix to increase the hardness of AMMCs. This paper addresses the fabrication of AMMCs and the optimization of WEDM process parameters for machining AMMCs to improve key performance characteristics, namely MRR, SR and KW. 


\section{Problem description}

The increased use of new and harder materials such as metal matrix composites in the aerospace, nuclear, missile, turbine, automobile, tool and die industries necessitates the application of NTM processes. The use of the WEDM with improper parameter setting will result in a less precise geometric shapes and inferior surface quality and a long time is required to manufacture cutting tools. WEDM is considered to be a challenging process as it involves optimization of more than one process parameter to attain required performance characteristics. The optimization of WEDM process parameters is multi-objective in nature. In general, the optimization of multi-objective problems is cumbersome and innovative solution methods need to be used. The prime objective of this study is to obtain optimal WEDM process parameters for machining AMMCs with the maximum MRR and the minimum SR and KW.

\section{Methodology}

To improve a machining process with a single performance characteristic, the optimal selection of key process parameters by using the Taguchi method has been extensively adopted. The key process parameters of WEDM are servo voltage (V), pulse on time or Ton $(\mu \mathrm{s})$, pulse off time or Toff $(\mu \mathrm{s})$, wire feed $(\mathrm{m} / \mathrm{min})$, wire tension $(\mathrm{N})$, and volume $\%$ of $\mathrm{B}_{4} \mathrm{C}$. This study focuses on the optimization performance characteristics MRR, KW and SR. However, the traditional Taguchi method cannot be used to solve multi-objective optimization problems. To overcome this, the Taguchi-based grey relational analysis is used to optimize the multi-objective criteria. With the grey relational analysis, a grey relational grade is obtained to evaluate the multiple performance characteristics (Udaya Prakash, J. et al. 2018).

The methodology consists of the following steps:

I. Fabrication of AMMCs

II. Conducting scanning electron microscopy (SEM analysis), energy dispersive $\mathrm{X}$-ray (EDAX) analysis and testing the hardness of AMMCs

III. Design of experiments comprising of: a. design of and conducting the screening experiment, $b$. design of the machining experiments, c. identification of the interaction effect, d. conducting the main experiment e. analysis which includes the loss function, the determination of the grey relational coefficient, grey relational grading and ANOVA.

IV. Conducting the confirmation test

\subsection{Fabrication of aluminium metal matrix composites}

Aluminium alloy 6063 was taken on a volume basis for the $35 \mathrm{~mm} \times 35 \mathrm{~mm} \times 100 \mathrm{~mm}$ long square box mould made of steel. The reinforcement of $\mathrm{B}_{4} \mathrm{C}$ was done with three quantities having volume percentages of $3 \%, 6 \%$ and $9 \%$. The crucible was filled with aluminium and inserted in the stir casting furnace. Heat was generated by an electric coil. The furnace temperature was increased to $800^{\circ} \mathrm{C}$ to melt the metal. Simultaneously, $3 \%$ boron carbide powder was heated in a muffle furnace at $400^{\circ} \mathrm{C}$ and kept in the crucible. After that, boron carbide was mixed with liquid aluminium using a stirrer rotating at $800 \mathrm{rpm}$. Stirring was carried out for 30 minutes at the same temperature and then the molten metal was poured into the steel mould. The same process was repeated with other two samples having volume percentages of $6 \%$ and $9 \%$ boron carbide. 
G. Navakodi, N. Jawahar, PL.K. Palaniappan
Parameter Optimization of the CNC Wire-Cut EDM Process for Machining Aluminium 6063-B4C Metal Matrix Composites

\subsection{SEM and EDAX analysis}

Three combinations of $\mathrm{B}_{4} \mathrm{C}$-reinforced AMMCs were tested in a CARL ZEISS, EVO18 scanning electron microscope and an AMETEK-EDAX, PV 6500 energy dispersive X-ray spectrometer. SEM images of the three combinations of the AMMCs are shown in Figs. 1, 2 and 3.

\section{EDAX APEX}

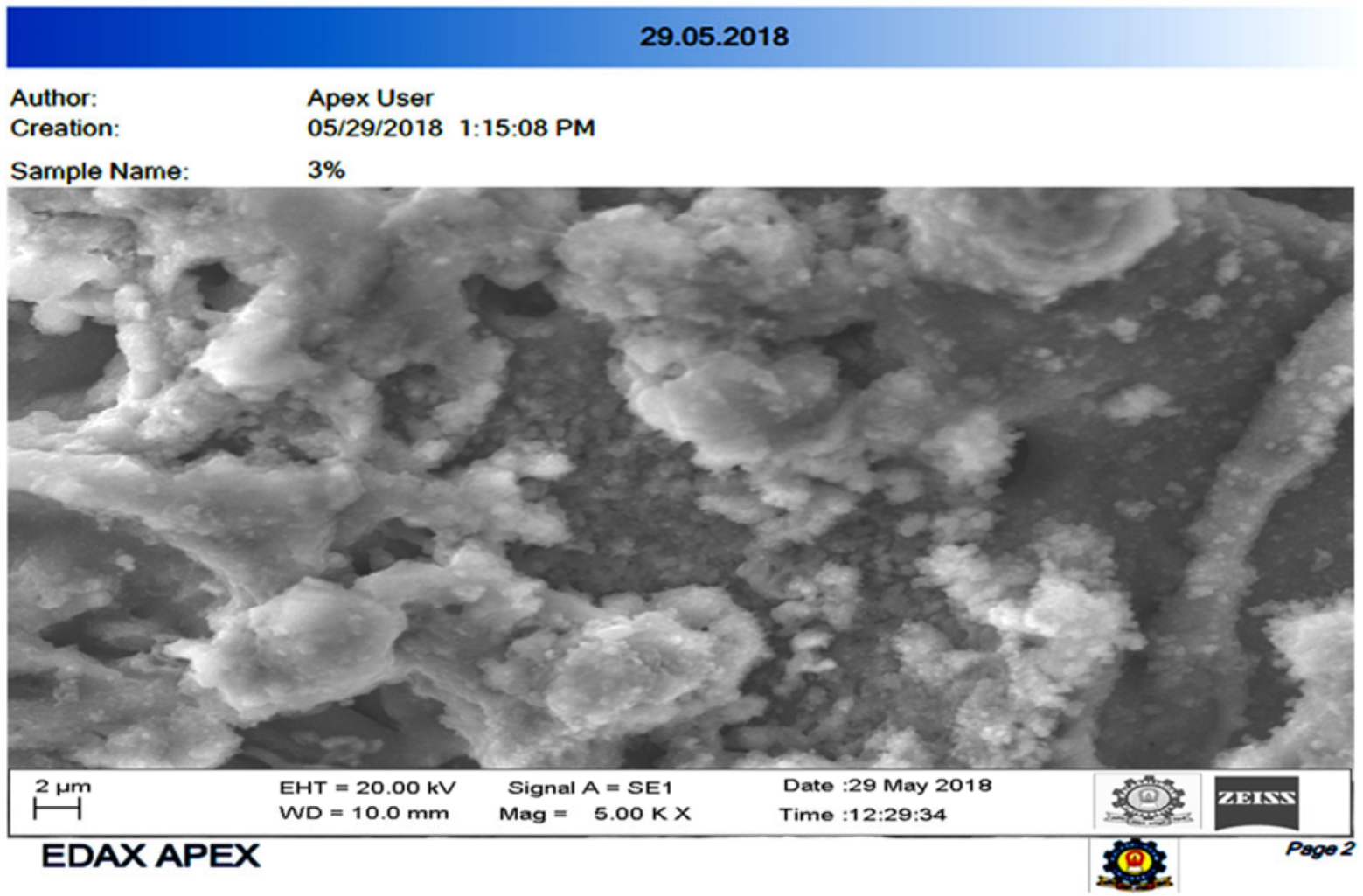

Full Area 1

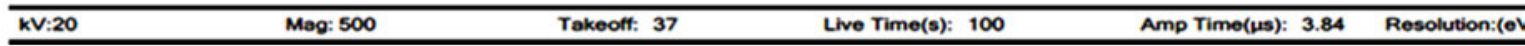

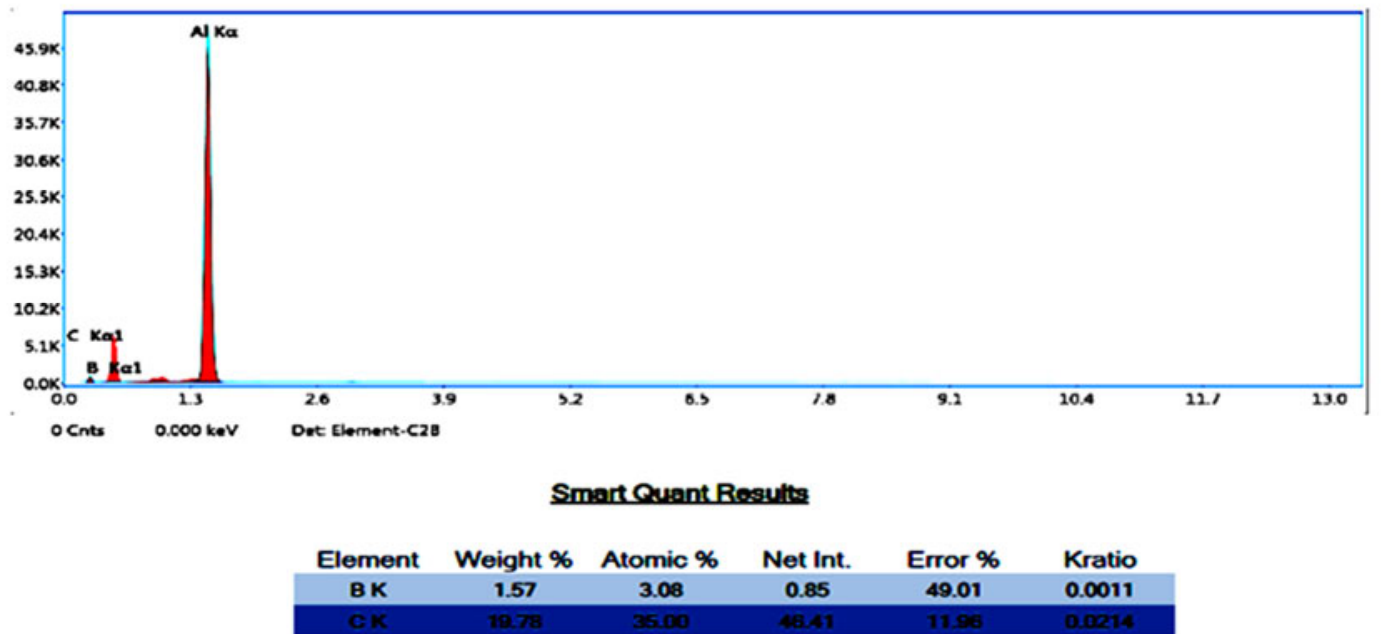

Fig. 1 SEM and EDAX image of 3\% $\mathrm{B}_{4} \mathrm{C}$ and AL6063 
Parameter Optimization of the CNC Wire-Cut EDM Process for Machining Aluminium 6063-B4C Metal Matrix Composites
G. Navakodi, N. Jawahar, PL.K. Palaniappan

\section{EDAX APEX}

\subsubsection{8}

\section{Author:}

Creation:

Apex User

Sample Name:

05/29/2018 1:07:15 PM

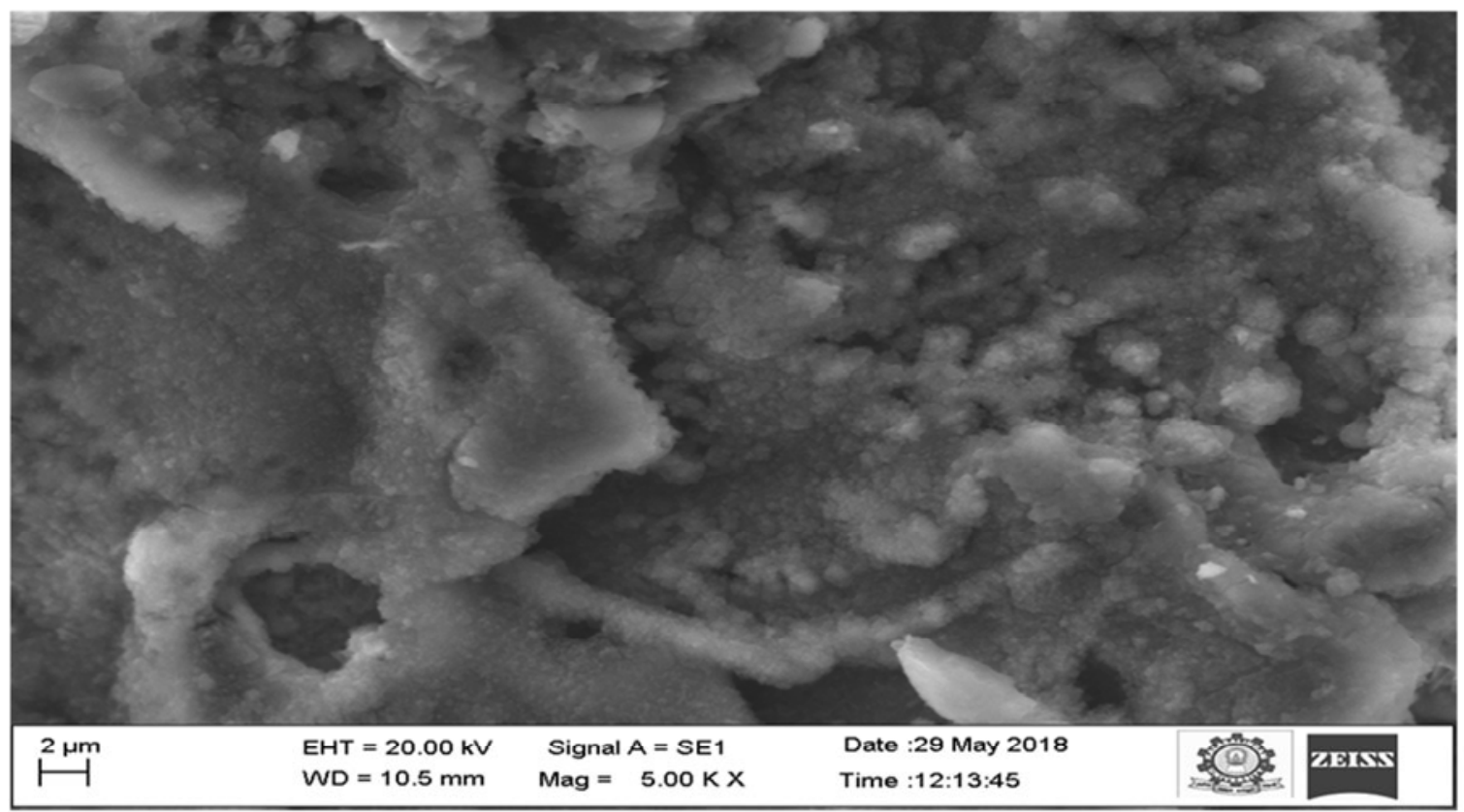

EDAX APEX

Page 2

\section{Full Area}

\begin{tabular}{llllll}
\hline KV:20 & Mag: 500 & Takeoft: 37 & Live Time(s): 100 & Amp Time(us): 3.84 & Resolution:(eV) 127.7 \\
\hline
\end{tabular}

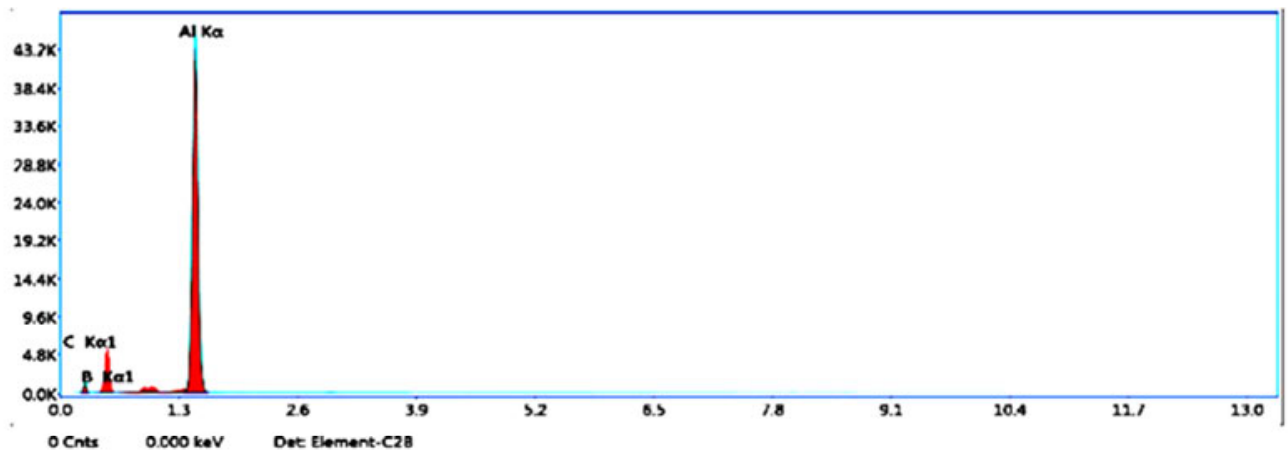

Smart Quant Results

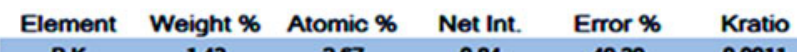

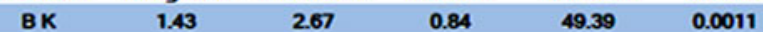

Fig. 2 SEM and EDAX image of $6 \% \mathrm{~B}_{4} \mathrm{C}$ and AL6063 
G. Navakodi, N. Jawahar, PL.K. Palaniappan
Parameter Optimization of the CNC Wire-Cut EDM Process for Machining Aluminium 6063-B4C Metal Matrix Composites

EDAX APEX

\subsubsection{8}

$\begin{array}{ll}\text { Author: } & \text { Apex User } \\ \text { Creation: } & \text { 05/29/2018 12:57:22 PM } \\ \text { Sample Name: } & 9 \%\end{array}$

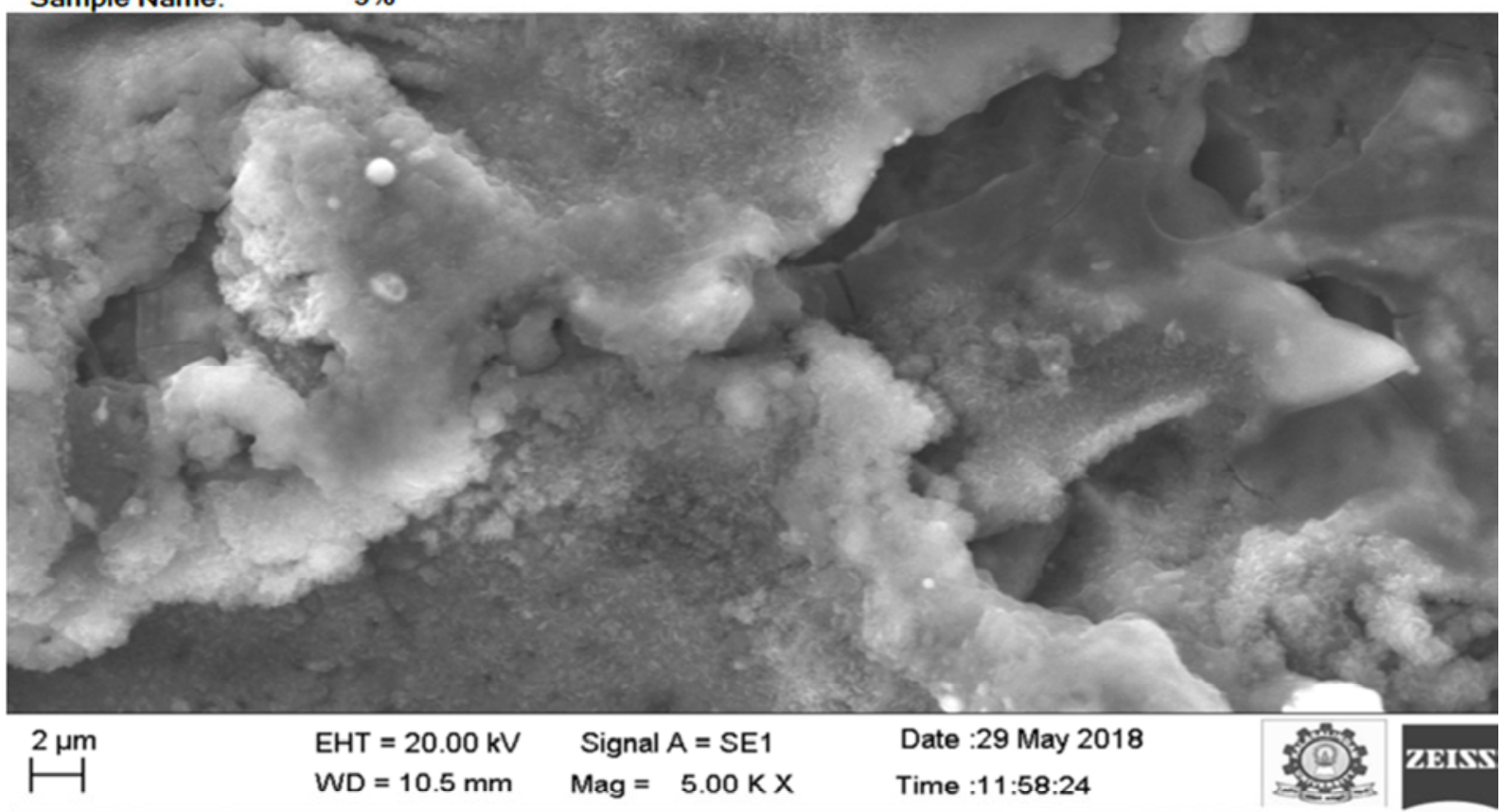

EDAX APEX

Page 2

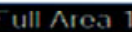

\begin{tabular}{llllll}
\hline KV:20 & Mag: 500 & Takeoff: 37 & Live Time(s): 100 & Amp Time(us): 3.84 & Resolution:(oV) 127.7 \\
\hline
\end{tabular}

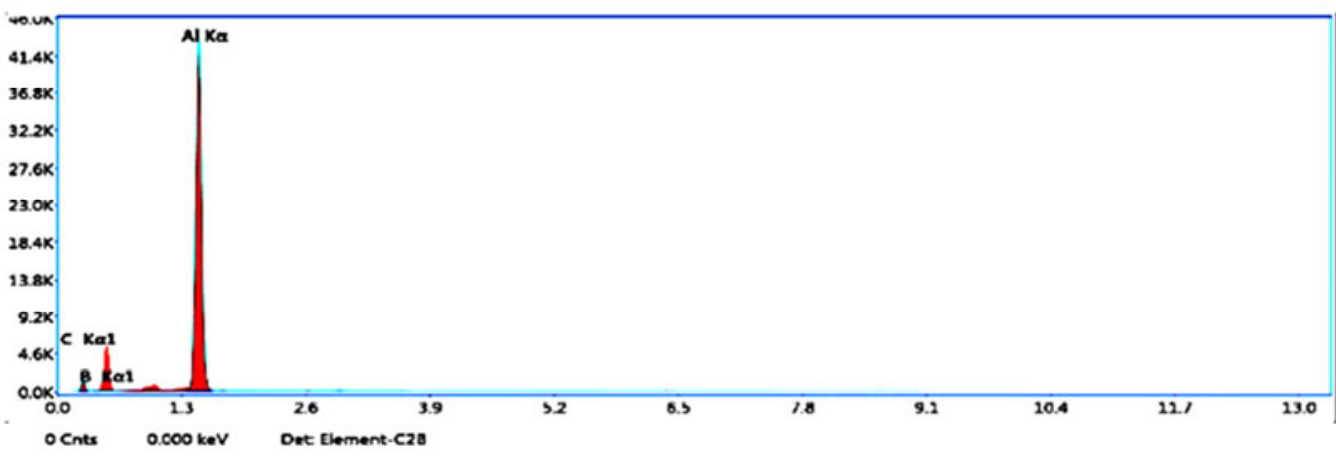

Smart Quant Results

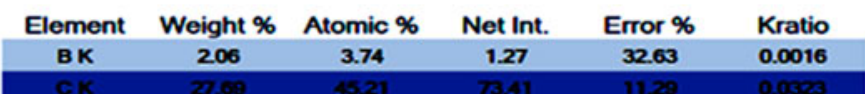

Fig. 3 SEM and EDAX image of 9\% $\mathrm{B}_{4} \mathrm{C}$ and AL6063

\subsubsection{Testing of hardness of AMMCs}

The AMMCs were tested using a NOBLE hardness testing machine to examine the improvement in the hardness value when $\mathrm{B}_{4} \mathrm{C}$ was added. The Brinell hardness values are shown in Table 1. 
Table 1 Brinell hardness values

\begin{tabular}{|c|c|c|c|}
\hline AMMC & $\boldsymbol{B H N}$ & $\begin{array}{c}\text { Improvement in } \\
\text { hardness BHN }\end{array}$ & $\begin{array}{c}\text { Improvement in } \\
\text { hardness (\%) }\end{array}$ \\
\hline $0 \% B_{4}$ C Al6063 & $* *(25.00) 33.00$ & 0 & 0 \\
\hline $3 \% B_{4}$ C Al6063 & 40.78 & 7.78 & 23.58 \\
\hline $6 \% B_{4}$ C Al6063 & 52.78 & 19.78 & 59.94 \\
\hline $9 \% B_{4}$ C Al6063 & 61.66 & 28.66 & 86.85 \\
\hline
\end{tabular}

** Reference - www.azom.com

It can be observed that the hardness of AMMCs improves with an increase in the percentage of $\mathrm{B}_{4} \mathrm{C}$.

\subsection{Design of experiments}

The full factorial method leads to an increase in the cost and time consumption in a real life situation, when there is an increase in the number of parameters with multiple levels and performance characteristics. Fractional factorial design was used to minimize the number of experiments. The WEDM process parameters that have influence on the response variables were identified. The levels and parameters were identified and set for conducting the screening experiment. In the screening experiment, the interaction effect between the process parameters and the performance measure was found. An orthogonal array (OA) for the main experiment was selected after analysing the interaction effect between the parameters and the performance characteristics (Chockalingam et al., 2012).

\subsubsection{Machining experiment}

The experiment was conducted using an Electronica CNC WED machine, model ECOCUT. The machine is equipped with ELCAM part programming software and it has four axes, $\mathrm{X}, \mathrm{Y}, \mathrm{u}$ and $\mathrm{v}$, shown in Fig. 4. The accuracy of the machine is $0.001 \mathrm{~mm}$, and a zinc coated copper wire of $0.25 \mathrm{~mm}$ in diameter was used as a cutting tool. De-ionized water was used as a dielectric medium.

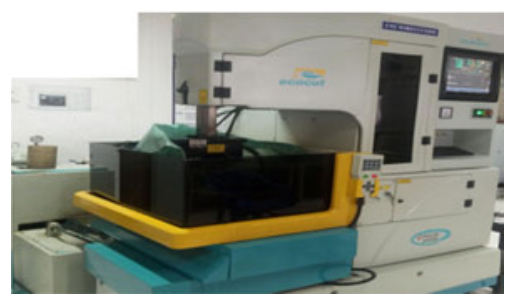

Fig. 4 Experimental setup

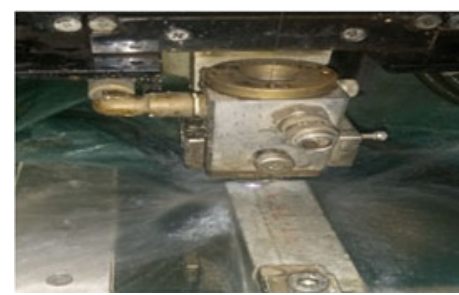

Fig. 5 Cutting process

The process considered is the slicing of AMMCs reinforced with boron carbide in three different combinations and in the form of a square bar. The tool material was $0.25 \mathrm{~mm}$ diameter zinc coated copper wire. The specific resistance of the dielectric medium was maintained at $10-15 \mu$ Siemens $/ \mathrm{cm}$. The cross section of the cutting area was $34 \mathrm{~mm} \times 34$ mm. Fig. 5 shows the slicing of the AMMCs.

\subsubsection{Identification of process parameters}

CNC WEDM parameters are pulse on time (Ton), pulse off time (Toff), peak current, peak voltage, servo voltage (SV), servo feed, wire tension, and wire feed. The identified key parameters are Ton, Toff, SV, wire feed, wire tension and volume $\%$ of $\mathrm{B}_{4} \mathrm{C}$. 
G. Navakodi, N. Jawahar, PL.K. Palaniappan
Parameter Optimization of the CNC Wire-Cut EDM Process for Machining Aluminium 6063-B4C Metal Matrix Composites

\subsubsection{Levels and parameter setting for the screening experiment}

In order to identify the interaction effect between the process parameters and the performance characteristics, screening experiments were conducted. For the above considered parameters the minimum and the maximum levels of each parameter were set for conducting the screening experiments. Table 2 shows the selected parameters and their levels.

Table 2 Experimental levels and parameters

\begin{tabular}{|c|c|c|c|}
\hline No. and symbol & Controllable factors & Low level 1 & High level 2 \\
\hline$I(A)$ & $S V(\mathrm{~V})$ & 22 & 30 \\
\hline $2(B)$ & Ton $(\mu \mathrm{s})$ & 114 & 122 \\
\hline $3(C)$ & Toff $(\mu \mathrm{s})$ & 48 & 52 \\
\hline $4(D)$ & Volume \% of $B_{4} C$ & 3 & 9 \\
\hline $5(E)$ & Wire feed $(\mathrm{m} / \mathrm{min})$ & 3 & 5 \\
\hline $6(F)$ & Wire tension $(\mathrm{N})$ & 39.24 & 58.86 \\
\hline
\end{tabular}

The OA for the screening experiment was selected as L12 on the basis of the parameters and the number of levels of each parameter. Six machining parameters were chosen as control factors and each parameter had two levels, namely the maximum and the minimum level. Out of the six machining parameters SV, Ton and Toff were taken for the interaction analysis and the other three had no significant interaction among themselves. (Chockalingam et al., 2012).

\subsubsection{Screening experiment}

The AMMCs square $(34 \mathrm{~mm} * 34 \mathrm{~mm}$ ) bars (three specimens) were sliced into 12 square and $5 \mathrm{~mm}$ thick pieces by the WED machine using the process parameters presented in Table 2. The measurement of KW and roughness are measured and the MRR was calculated. Fig. 6 shows the screening experimental pieces.

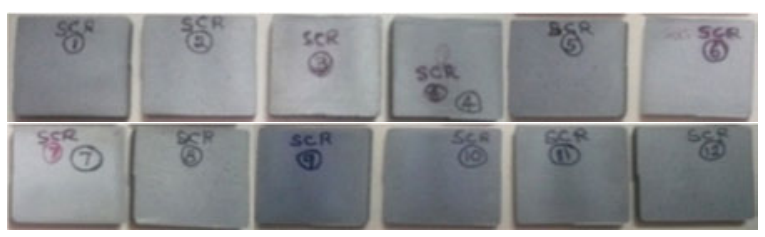

Fig. 6 Screening experimental WEDM specimen pieces (12 pieces)

\subsubsection{Performance measurement}

The SR was measured by using a Mitutoyo SJ-410 surface roughness measuring machine with an accuracy of one micro meter. The KW was measured in mm by using a Mitutoyo PH600 profile projector with an accuracy of one micron. The MRR was calculated from the equation

$$
\mathrm{MRR}=K W \cdot V c \cdot H \quad(\text { Chockalingam et al., 2012,Ref. No. 11) }
$$

where $V_{\mathrm{c}}-$ mean cutting speed $(\mathrm{mm} / \mathrm{min})$, taken directly from the Electronica ELPULS15 CNC WEDM, $H$ - height of the workpiece $(\mathrm{mm}), K W$ - width of the cut in mm.

The performance characteristics were taken at two positions and the average was taken for the analysis. The performance characteristics are given in Table 3. 
Table 3 Values of performance characteristics

\begin{tabular}{|c|c|c|c|c|c|c|c|c|c|}
\hline Response & \multicolumn{3}{|c|}{ SR $(\boldsymbol{\mu m})$} & \multicolumn{3}{c|}{$K W(\mathbf{m m})$} & \multicolumn{3}{c|}{ MRR $\left(\mathbf{m m}^{\mathbf{3}} / \mathbf{m i n}\right)$} \\
\hline Trial No. & Position 1 & Position 2 & Average & Position 1 & Position 2 & Average & Position 1 & Position 2 & Average \\
\hline 1 & 4.702 & 4.219 & 4.461 & 0.336 & 0.332 & 0.334 & 19.992 & 19.754 & 19.873 \\
\hline 2 & 3.700 & 3.441 & 3.571 & 0.34 & 0.346 & 0.343 & 19.883 & 20.234 & 20.059 \\
\hline 3 & 3.007 & 3.239 & 3.123 & 0.346 & 0.364 & 0.355 & 15.881 & 16.708 & 16.295 \\
\hline 4 & 5.266 & 5.150 & 5.208 & 0.354 & 0.370 & 0.362 & 39.358 & 41.137 & 40.247 \\
\hline 5 & 4.889 & 4.587 & 4.738 & 0.396 & 0.370 & 0.383 & 36.757 & 34.343 & 35.550 \\
\hline 6 & 3.675 & 3.971 & 3.823 & 0.382 & 0.392 & 0.387 & 36.626 & 37.585 & 37.106 \\
\hline 7 & 4.389 & 4.593 & 4.491 & 0.306 & 0.302 & 0.304 & 11.579 & 11.646 & 11.613 \\
\hline 8 & 4.249 & 4.999 & 4.624 & 0.314 & 0.288 & 0.301 & 10.249 & 9.4003 & 9.8246 \\
\hline 9 & 4.320 & 4.792 & 4.556 & 0.314 & 0.334 & 0.324 & 19.642 & 18.962 & 19.302 \\
\hline 10 & 3.073 & 3.751 & 3.412 & 0.322 & 0.366 & 0.344 & 27.193 & 28.217 & 27.705 \\
\hline 11 & 4.677 & 4.330 & 4.504 & 0.382 & 0.384 & 0.383 & 41.042 & 41.257 & 41.150 \\
\hline 12 & 4.657 & 4.405 & 4.531 & 0.36 & 0.390 & 0.375 & 36.965 & 40.045 & 38.505 \\
\hline
\end{tabular}

From the screening experiments, the two way interaction between SV Vs other all parameters were analysed and the interaction plots are shown in Fig. 7.

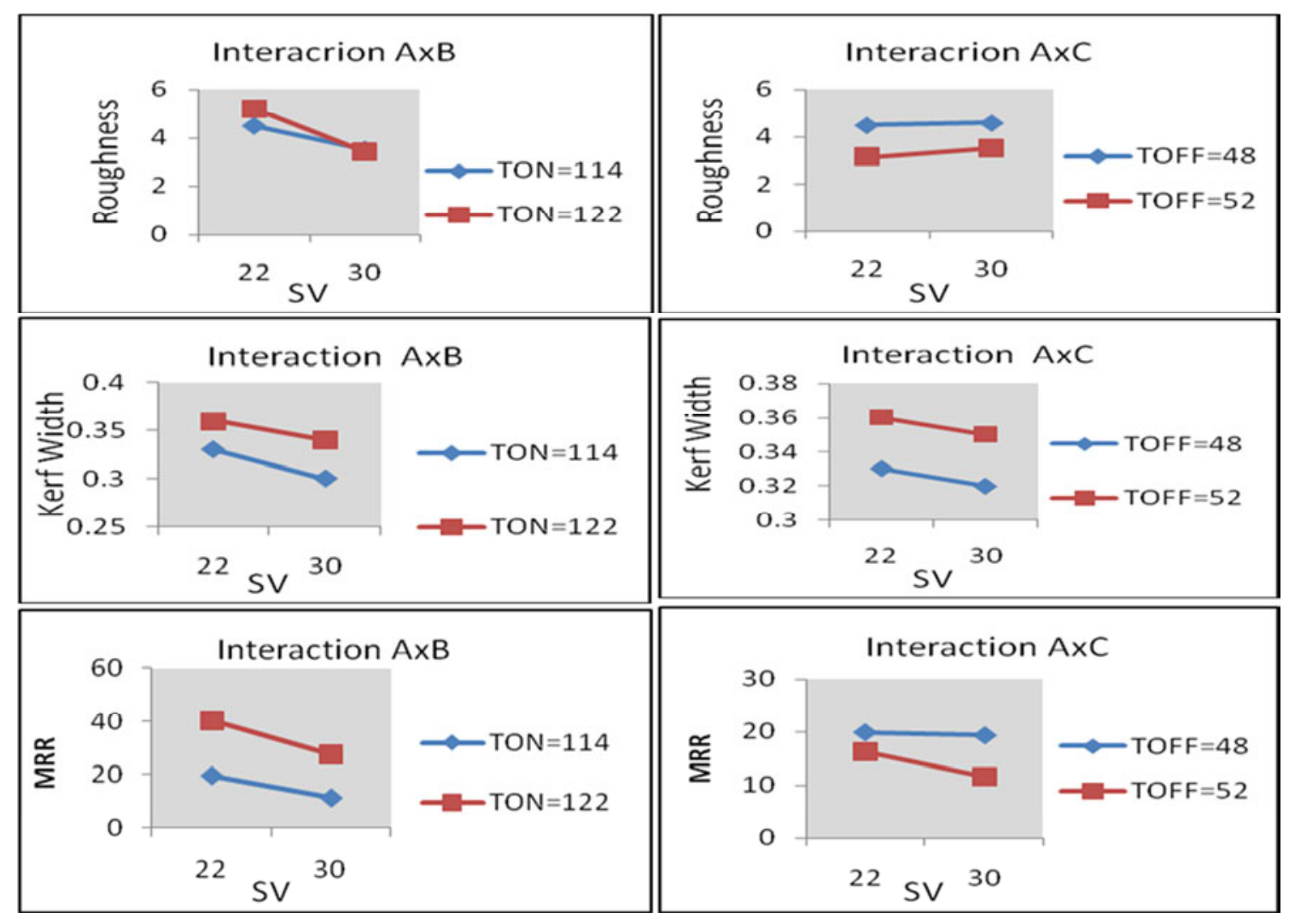

Fig. 7 Interaction between parameters

The interaction plot confirms that there is no two-way interaction available for the selected parameters. Hence, in the main experiment, the interaction column for the $\mathrm{L}_{18}$ orthogonal array was not considered.

\subsubsection{Selection of an orthogonal array (OA)}

The OA design is a standard experimental design that requires only a small number of experimental trials for the main factor effects on the output to be found. 
G. Navakodi, N. Jawahar, PL.K. Palaniappan
Parameter Optimization of the CNC Wire-Cut EDM Process for Machining Aluminium 6063-B4C Metal Matrix Composites

The OA was selected for the main experiment based on the number of parameters, interactions between them and the number of levels of each parameter. As the nature of the curve at the intermediate levels is not predictable, three levels were set, i.e. the lower, the medium and the higher level were considered for the calculation of the quadratic effect of the particular process parameter on the response variable. For the main experiment, L18 OA was used as there was no interaction between the most influencing parameters, namely Ton and Toff on MRR, SR and KW. The details of the parameter setting are given in Table 4. Peak current (IP) is the amount of power required during Ton. Gap voltage (VP) is the supply voltage to be placed on the gap between wire and workpiece. Servo feed (SF) are control limits of the speed of wire (Table movement).

Table 4 Variable parameters and levels

\begin{tabular}{|c|c|c|c|c|}
\hline No. and symbol & Controllable factors & Low level & Medium level & High level \\
\hline $1(A)$ & $S V(\mathrm{~V})$ & 22 & 26 & 30 \\
\hline $2(B)$ & Ton $(\mu \mathrm{s})$ & 114 & 118 & 122 \\
\hline $3(C)$ & Toff $(\mu \mathrm{s})$ & 48 & 50 & 52 \\
\hline $4(D)$ & Volume\% of $B_{4} C$ & 3 & 6 & 9 \\
\hline $5(E)$ & Wire feed $(\mathrm{m} / \mathrm{min})$ & 3 & 4 & 5 \\
\hline $6(F)$ & Wire tension $(\mathrm{N})$ & 39.24 & 49.05 & 58.86 \\
\hline
\end{tabular}

Constant parameters: $\mathrm{IP}=12(\mathrm{~A}), \mathrm{VP}=11(\mathrm{~V}), \mathrm{SF}=2100(\mathrm{~mm} / \mathrm{min} / \mathrm{s})$

\subsubsection{Main experiment}

Fig. 8 shows the main 18 experimental specimen pieces sliced by the WED machine. Table 5 shows the measured values taken for the main experiment analysis at three levels of the three machining performance characteristics, namely surface roughness, KW size and MRR. Table 5 shows the setting of the L18 orthogonal array with parameters and levels.

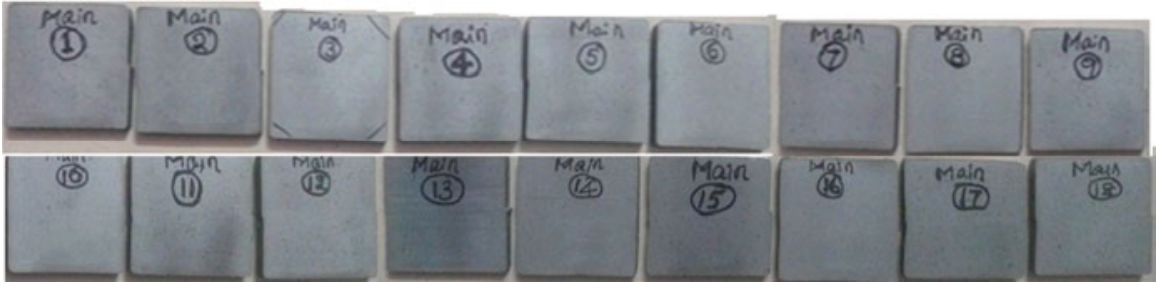

Fig. 8 Main experimental WEDM specimen pieces

Table 5 L18 orthogonal array with parameters

\begin{tabular}{|c|c|c|c|c|c|c|}
\hline Run & $\begin{array}{c}S V(\mathbf{V}) \\
(\boldsymbol{A})\end{array}$ & $\begin{array}{c}\text { Ton }(\boldsymbol{\mu s}) \\
(\boldsymbol{B})\end{array}$ & $\begin{array}{c}\text { Toff }(\boldsymbol{\mu} \mathbf{s}) \\
(\boldsymbol{C})\end{array}$ & $\begin{array}{c}\text { Volume \% of B } \boldsymbol{H}_{\mathbf{C}} \\
(\boldsymbol{D})\end{array}$ & $\begin{array}{c}\text { Wire feed }(\mathbf{m} / \mathbf{m i n}) \\
(\boldsymbol{E})\end{array}$ & $\begin{array}{c}\text { Wire tension }(\mathbf{N}) \\
(\boldsymbol{F})\end{array}$ \\
\hline 1 & 22 & 114 & 48 & 3 & 3 & 39.24 \\
\hline 2 & 22 & 114 & 50 & 6 & 4 & 49.05 \\
\hline 3 & 22 & 114 & 52 & 9 & 5 & 58.86 \\
\hline 4 & 22 & 118 & 48 & 3 & 4 & 49.05 \\
\hline 5 & 22 & 118 & 50 & 6 & 5 & 58.86 \\
\hline 6 & 22 & 118 & 52 & 9 & 3 & 39.24 \\
\hline 7 & 22 & 122 & 48 & 6 & 3 & 58.86 \\
\hline 8 & 22 & 122 & 50 & 9 & 4 & 39.24 \\
\hline 9 & 22 & 122 & 52 & 3 & 5 & 49.05 \\
\hline 10 & 26 & 114 & 48 & 9 & 5 & 49.05 \\
\hline
\end{tabular}




\begin{tabular}{|c|c|c|c|c|c|c|}
\hline \multicolumn{6}{|l|}{ Table 5 continued } \\
\hline 11 & 26 & 114 & 50 & 3 & 3 & 58.86 \\
\hline 12 & 26 & 114 & 52 & 6 & 4 & 39.24 \\
\hline 13 & 26 & 118 & 48 & 6 & 5 & 39.24 \\
\hline 14 & 26 & 118 & 50 & 9 & 3 & 49.05 \\
\hline 15 & 26 & 118 & 52 & 3 & 4 & 58.86 \\
\hline 16 & 26 & 122 & 48 & 9 & 4 & 58.86 \\
\hline 17 & 26 & 122 & 50 & 3 & 5 & 39.24 \\
\hline 18 & 26 & 122 & 52 & 6 & 3 & 49.05 \\
\hline
\end{tabular}

Table 6 Actual response values of three uncontrollable factors

\begin{tabular}{|c|c|c|c|c|c|c|c|c|c|}
\hline Response & \multicolumn{3}{|c|}{$\begin{array}{c}\text { SR } \\
\text { R }(\boldsymbol{\mu m})\end{array}$} & \multicolumn{3}{c|}{$\begin{array}{c}\text { KW } \\
(\mathbf{m m})\end{array}$} & \multicolumn{3}{c|}{$\begin{array}{c}\text { MRR } \\
\left(\mathbf{m m}^{3} / \mathbf{m i n}\right)\end{array}$} \\
\hline Trial No. & 1 & 2 & 3 & 1 & 2 & 3 & 1 & 2 & 3 \\
\hline 1 & 3.459 & 3.430 & 3.504 & 0.316 & 0.292 & 0.298 & 13.549 & 12.520 & 12.778 \\
\hline 2 & 3.542 & 3.554 & 3.552 & 0.326 & 0.323 & 0.324 & 15.393 & 15.252 & 15.299 \\
\hline 3 & 3.544 & 3.562 & 3.592 & 0.328 & 0.332 & 0.324 & 16.253 & 16.451 & 16.055 \\
\hline 4 & 4.975 & 4.888 & 3.857 & 0.342 & 0.337 & 0.328 & 24.136 & 23.784 & 23.148 \\
\hline 5 & 3.960 & 3.584 & 3.846 & 0.346 & 0.335 & 0.343 & 25.911 & 25.087 & 25.687 \\
\hline 6 & 3.653 & 3.848 & 3.723 & 0.342 & 0.354 & 0.348 & 26.465 & 27.394 & 26.929 \\
\hline 7 & 4.485 & 4.564 & 4.555 & 0.368 & 0.364 & 0.362 & 31.609 & 31.265 & 31.093 \\
\hline 8 & 4.534 & 4.516 & 4.380 & 0.366 & 0.361 & 0.362 & 32.747 & 32.300 & 32.389 \\
\hline 9 & 4.586 & 4.473 & 4.442 & 0.374 & 0.368 & 0.372 & 36.018 & 35.440 & 35.825 \\
\hline 10 & 2.946 & 2.969 & 3.126 & 0.332 & 0.329 & 0.332 & 17.922 & 17.760 & 17.922 \\
\hline 11 & 3.197 & 2.938 & 2.968 & 0.328 & 0.332 & 0.336 & 18.194 & 18.416 & 18.638 \\
\hline 12 & 3.144 & 3.114 & 3.088 & 0.333 & 0.338 & 0.331 & 19.185 & 19.473 & 19.070 \\
\hline 13 & 3.987 & 3.954 & 3.911 & 0.359 & 0.348 & 0.354 & 27.504 & 26.661 & 27.121 \\
\hline 14 & 3.992 & 3.982 & 3.992 & 0.365 & 0.357 & 0.353 & 28.788 & 28.157 & 27.841 \\
\hline 15 & 3.989 & 4.186 & 4.088 & 0.364 & 0.363 & 0.358 & 30.825 & 30.741 & 30.317 \\
\hline 16 & 4.119 & 4.024 & 4.198 & 0.366 & 0.368 & 0.369 & 39.063 & 39.276 & 39.383 \\
\hline 17 & 4.325 & 4.428 & 4.251 & 0.366 & 0.372 & 0.368 & 38.011 & 38.635 & 38.219 \\
\hline 18 & 4.392 & 4.398 & 4.405 & 0.365 & 0.368 & 0.369 & 40.321 & 40.652 & 40.763 \\
\hline
\end{tabular}

\subsection{Analysis}

\subsubsection{Loss function}

After obtaining the data, the collection response values and signal-to-noise ratio were calculated. The value of the loss function was further transformed into a signal-to-noise ratio. The loss functions for the SR and $\mathrm{KW}$ were taken as lower-the-better performance characteristics and expressed as

$$
L_{i j}=\frac{1}{n} \sum_{k=1}^{n} Y_{i j k}^{2}
$$

where $\quad L_{i j}=$ loss function

$Y_{i j k}=$ experimental value

$n=$ number of trials 
The loss function for the MRR was taken as higher-the-better performance characteristics and expressed as

$$
L_{i j}=\frac{1}{n} \sum_{k=1}^{n} 1 / Y_{i j k}^{2}
$$

where $\quad L_{i j}=$ loss function

$Y_{i j k}=$ experimental value

$n=$ number of trials

\subsection{2 $\mathrm{S} / \mathrm{N}$ ratio of the multiple performance characteristics}

$\mathrm{S} / \mathrm{N}$ ratio $\eta_{i j}$ was used to find the deviation of the performance characteristics from the desired value. Table 5 shows the $\mathrm{S} / \mathrm{N}$ values of all performance characteristics.

$$
\eta_{i j}=-10 \log \left(L_{i j}\right) .
$$

\subsubsection{Normalized $\mathrm{S} / \mathrm{N}$ ratio}

The normalized $\mathrm{S} / \mathrm{N}$ ratio $X_{i j}$ which depends on the performance characteristics in the experiment can be expressed in two categories, i.e. the higher the better and the lower the better category. Here, the performance of the MRR was defined as the higher the better category. The equation for the higher the better category is

$$
X_{i j}=\frac{\eta_{i j}-\min _{j} \eta_{i j}}{\max _{j} \eta_{i j}-\min _{j} \eta_{i j}}
$$

The performance of the SR and KW was defined as the lower the better. The equation for the lower the better category is

$$
X_{i j}=\frac{\max _{j} \eta_{i j}-\eta_{i j}}{\max _{j} \eta_{i j}-\min _{j} \eta_{i j}}
$$

where $\quad \eta_{i j}=\mathrm{S} / \mathrm{N}$ ratio.

\subsubsection{Grey relational co-efficient}

The grey relational co-efficient was calculated to represent the relationship between the ideal (best) and the actual normalized $\mathrm{S} / \mathrm{N}$ ratio.

$$
\delta_{i j}=\frac{\min _{i} \min _{j}\left|X_{i}^{0}-X_{i j}\right|+\xi \max _{i} \max _{j}\left|X_{i}^{0}-X_{i j}\right|}{\left|X_{i}^{0}-X_{i j}\right|+\xi \max _{i} \max _{j}\left|X_{i}^{0}-X_{i j}\right|}
$$

where

$$
\begin{aligned}
& X_{i}^{0}=\text { ideal normalized } \mathrm{S} / \mathrm{N} \text { ratio } \\
& X_{i j}=\text { normalized } \mathrm{S} / \mathrm{N} \text { ratio } \\
& \xi=\text { distinguishing co-efficient which is defined in the range } 0 \leq \xi \leq 1 .
\end{aligned}
$$

\subsubsection{Grey relational grade}

The grey relational grade was used to find the overall evaluation of the multiple performance characteristics. The highest grey relational grade shows that the corresponding $\mathrm{S} / \mathrm{N}$ ratio is closer to the ideally normalized $\mathrm{S} / \mathrm{N}$ ratio.

$$
\gamma_{i j}=\frac{1}{m} \sum_{i=1}^{m} \omega_{j} \delta_{i j}
$$


Parameter Optimization of the CNC Wire-Cut EDM Process

for Machining Aluminium 6063-B4C Metal Matrix Composites
G. Navakodi, N. Jawahar, PL.K. Palaniappan

where $\quad m=$ number of performance characteristics

$\delta_{i j}=$ grey relational co-efficient

$\omega_{j}=$ weighting factor

$\omega_{i}=0.33$ for all performances (Shyam Lalet al., 2014).

Table $7 \mathrm{~S} / \mathrm{N}$ ratio for $\mathrm{SR}, \mathrm{KW}$ and MRR

\begin{tabular}{|c|c|c|c|}
\hline Exp. No. & $\begin{array}{c}\text { S/N ratio values (dB) } \\
\text { the lower the better) } \\
\text { of SR }\end{array}$ & $\begin{array}{c}\text { S/N ratio values (dB) } \\
\text { the lower the better) } \\
\text { of } \mathbf{K} \boldsymbol{W}\end{array}$ & $\begin{array}{c}\text { S/N ratio values (dB) } \\
\text { (the higher the better) } \\
\text { of MRR }\end{array}$ \\
\hline 1 & -10.7916 & 10.39986 & 22.24472 \\
\hline 2 & -11.0021 & 9.789100 & 23.70064 \\
\hline 3 & -11.0436 & 9.682523 & 24.21974 \\
\hline 4 & -11.0607 & 9.473214 & 27.49020 \\
\hline 5 & -11.5888 & 9.344912 & 28.15156 \\
\hline 6 & -11.9121 & 9.168415 & 28.60473 \\
\hline 7 & -13.1315 & 8.754143 & 29.91727 \\
\hline 8 & -13.2116 & 8.801867 & 30.23125 \\
\hline 9 & -13.0643 & 8.612522 & 31.06771 \\
\hline 10 & -9.58286 & 9.603440 & 25.04055 \\
\hline 11 & -9.64031 & 9.577238 & 25.30343 \\
\hline 12 & -9.86916 & 9.525071 & 25.68591 \\
\hline 13 & -11.9341 & 9.019935 & 28.65778 \\
\hline 14 & -12.0173 & 8.922339 & 29.02406 \\
\hline 15 & -12.2302 & 8.825829 & 29.72209 \\
\hline 16 & -12.2853 & 8.683044 & 31.87569 \\
\hline 17 & -12.7398 & 8.659473 & 31.66216 \\
\hline 18 & -12.8651 & 8.706679 & 32.16603 \\
\hline
\end{tabular}

Table 8 shows the grey relational coefficient for all performance characteristics of MRR, SR, and KW. It was calculated to communicate the relationship between the ideal (best) and the actual normalized $\mathrm{S} / \mathrm{N}$ ratio.

Table 8 Grey relational co-efficient (distinguishing co-efficient $=0.5$ )

\begin{tabular}{|c|c|c|c|}
\hline Exp. $\boldsymbol{N o}$. & $\boldsymbol{S R}$ & $\boldsymbol{K} \boldsymbol{W}$ & $\boldsymbol{M R R}$ \\
\hline 1 & 0.428482 & 0.333333 & 0.333333 \\
\hline 2 & 0.450904 & 0.431673 & 0.369480 \\
\hline 3 & 0.455604 & 0.455101 & 0.384340 \\
\hline 4 & 0.457561 & 0.509398 & 0.514779 \\
\hline 5 & 0.527869 & 0.549592 & 0.552711 \\
\hline 6 & 0.582679 & 0.616510 & 0.582103 \\
\hline 7 & 0.957742 & 0.863207 & 0.688080 \\
\hline 8 & 1.000000 & 0.825168 & 0.719412 \\
\hline 9 & 0.924887 & 1.000000 & 0.818728 \\
\hline 10 & 0.333334 & 0.474199 & 0.410442 \\
\hline 11 & 0.336889 & 0.480885 & 0.419568 \\
\hline 12 & 0.351840 & 0.494774 & 0.433594 \\
\hline 13 & 0.586827 & 0.686866 & 0.585749 \\
\hline
\end{tabular}




\begin{tabular}{|c|l|l|l|}
\hline \multicolumn{4}{|l|}{ Table 8 continued } \\
\hline 14 & 0.603043 & 0.742567 & 0.612228 \\
\hline 15 & 0.648974 & 0.807307 & 0.669943 \\
\hline 16 & 0.662014 & 0.926859 & 0.944707 \\
\hline 17 & 0.793622 & 0.950085 & 0.907793 \\
\hline 18 & 0.839650 & 0.904683 & 1.000000 \\
\hline
\end{tabular}

Distinguishing co-efficient for $\mathrm{MRR}=0.5, \mathrm{SR}=0.5$ and $\mathrm{KW}=0.5$

Table 9 shows the grey relational grade for all experiments. The maximum grade value was selected as optimal among 18 experiments.

Table 9 Grey relational grade (weight factor $=0.33$ )

\begin{tabular}{|c|c|c|}
\hline Exp. No. & Grey relational grade & Order \\
\hline 1 & 0.364732 & 18 \\
\hline 2 & 0.416873 & 15 \\
\hline 3 & 0.431208 & 13 \\
\hline 4 & 0.494121 & 12 \\
\hline 5 & 0.543484 & 11 \\
\hline 6 & 0.593647 & 6 \\
\hline 7 & 0.83486 & 4 \\
\hline 8 & 0.846909 & 2 \\
\hline 9 & 0.91358 & 17 \\
\hline 10 & 0.406036 & 16 \\
\hline 11 & 0.412518 & 14 \\
\hline 12 & 0.426804 & 9 \\
\hline 13 & 0.619474 & 8 \\
\hline 14 & 0.652209 & 7 \\
\hline 15 & 0.708353 & 5 \\
\hline 16 & 0.845528 & 1 \\
\hline 17 & 0.884073 & 3 \\
\hline 18 & 0.91563 & \\
\hline
\end{tabular}

The optimal parameter setting for Experiment No. 18 is

A- Servo voltage: $26 \mathrm{~V}$; B- Pulse on time: $122 \mu \mathrm{s}$; C -Pulse off time: $52 \mu \mathrm{s}$;

$\mathrm{D}$ - Volume $\%$ of $\mathrm{B}_{4} \mathrm{C}=6$; $\mathrm{E}-$ Wire feed $=3 \mathrm{~m} / \mathrm{min} ; \mathrm{F}$ - Wire tension: $49.05 \mathrm{~N}$

\subsubsection{Response table for grey relational grade}

Table 10 shows the effect of each machining parameter on the grey relational grades at three levels. From this response table the grey relational grade graph (Fig. 14) was prepared to obtain a graphical representation of optimal parameters that have an optimal combination of the multiple performance characteristics. 
Table 10 Response table

\begin{tabular}{|c|c|c|c|c|c|}
\hline \multirow{2}{*}{ Symbol } & \multirow{2}{*}{$\begin{array}{c}\text { Process } \\
\text { parameters }\end{array}$} & \multicolumn{3}{|c|}{ Grey relational grade } & \multirow{2}{*}{ Max-Min } \\
\cline { 3 - 5 } & & Level 1 & Level 2 & Level 3 & \\
\hline$A$ & $S V$ & 0.604379 & 0.652292 & NIL & 0.047912 \\
\hline$B$ & $T O N$ & 0.409695 & 0.601881 & 0.87343 & 0.463735 \\
\hline$C$ & $T O F F$ & 0.594125 & 0.626011 & 0.66487 & 0.070745 \\
\hline$D$ & $V O L \%$ & 0.629563 & 0.626188 & 0.629256 & 0.003375 \\
\hline$E$ & $W F$ & 0.628933 & 0.623098 & 0.632976 & 0.009878 \\
\hline$F$ & $W T$ & 0.622607 & 0.633075 & 0.629325 & 0.010468 \\
\hline \multicolumn{7}{|l|}{$\begin{array}{l}\text { Total mean value of the grey relational grade }=0.628336 \\
\text { Selected parameters for the confirmation test }=\text { A2-B3-C3-D1-E3-F2 }\end{array}$} \\
\hline
\end{tabular}

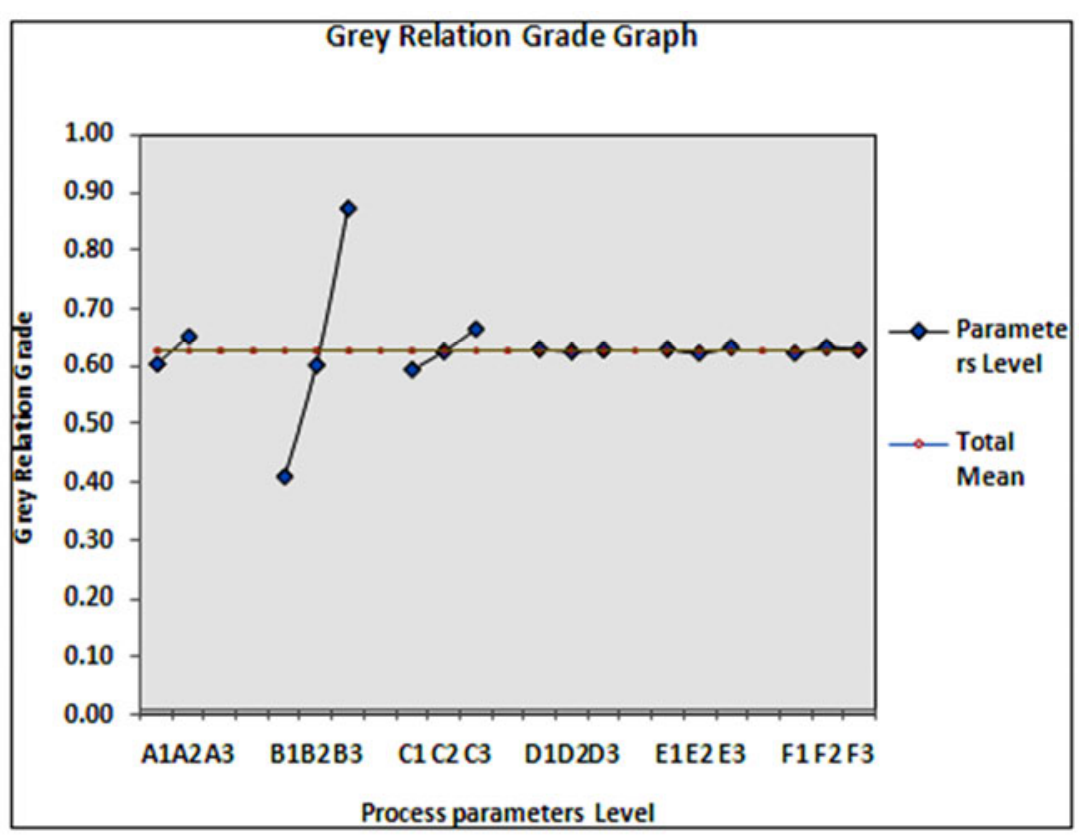

Fig. 9 Grey relational grade graph

\subsubsection{ANOVA}

Anova results for MRR, roughness and KW are shown in Tables 11, 12 and 13, respectively.

Table 11 ANOVA for MRR

\begin{tabular}{|c|c|c|c|c|c|c|}
\hline Symbol & $\begin{array}{c}\text { Process } \\
\text { parameters }\end{array}$ & DOF & Sum square & $\begin{array}{c}\text { Mean } \\
\text { square }\end{array}$ & $\begin{array}{c}\text { Variance } \\
\text { ratio }\end{array}$ & $\begin{array}{c}\text { Percentage } \\
\text { contribution }\end{array}$ \\
\hline$A$ & $S V$ & 1 & 86.12406 & 86.12406 & 47.98188 & 6.72980 \\
\hline$B$ & Ton & 2 & 1154.34 & 577.1701 & 321.556 & 90.20103 \\
\hline$C$ & Toff & 2 & 25.40976 & 12.70488 & 7.078208 & 1.985538 \\
\hline$D$ & \% of $B_{4} C$ & 2 & 0.320425 & 0.160212 & 0.089258 & 0.025038 \\
\hline$E$ & Wire feed & 2 & 0.567931 & 0.283965 & 0.158204 & 0.044379 \\
\hline$F$ & Wire tension & 2 & 2.209809 & 1.104904 & 0.61557 & 0.172676 \\
\hline ERROR & & 6 & 10.76957 & 1.794929 & 1 & 0.841543 \\
\hline TOTAL & & 17 & 1279.742 & & & 100 \\
\hline
\end{tabular}


G. Navakodi, N. Jawahar,

PL.K. Palaniappan
Parameter Optimization of the CNC Wire-Cut EDM Process for Machining Aluminium 6063-B4C Metal Matrix Composites

Table 12 ANOVA for roughness

\begin{tabular}{|c|c|c|c|c|c|c|}
\hline Symbol & $\begin{array}{c}\text { Process } \\
\text { parameters }\end{array}$ & DOF & $\begin{array}{c}\text { Sum } \\
\text { square }\end{array}$ & $\begin{array}{c}\text { Mean } \\
\text { square }\end{array}$ & $\begin{array}{c}\text { Variance } \\
\text { ratio }\end{array}$ & $\begin{array}{c}\text { Percentage } \\
\text { contribution }\end{array}$ \\
\hline$A$ & $S V$ & 1 & 0.119072 & 0.119072 & 1.67828 & 2.693026 \\
\hline$B$ & Ton & 2 & 3.766161 & 1.883081 & 26.54139 & 85.17847 \\
\hline$C$ & Toff & 2 & 0.078871 & 0.039436 & 0.55583 & 1.783809 \\
\hline$D$ & \% of $B_{4} C$ & 2 & 0.010377 & 0.005189 & 0.07313 & 0.234694 \\
\hline$E$ & Wire feed & 2 & 0.009991 & 0.004996 & 0.07041 & 0.225964 \\
\hline$F$ & Wire tension & 2 & 0.011329 & 0.005665 & 0.079839 & 0.256226 \\
\hline ERROR & & 6 & 0.425693 & 0.070949 & 1 & 9.627809 \\
\hline TOTAL & & 17 & 4.421494 & & & 100 \\
\hline
\end{tabular}

Table 13 ANOVA for KW

\begin{tabular}{|c|c|c|c|c|c|c|}
\hline Symbol & $\begin{array}{c}\text { Process } \\
\text { parameters }\end{array}$ & DOF & Sum Square & $\begin{array}{c}\text { Mean } \\
\text { square }\end{array}$ & $\begin{array}{c}\text { Variance } \\
\text { Ratio }\end{array}$ & $\begin{array}{c}\text { Percentage } \\
\text { Contribution }\end{array}$ \\
\hline$A$ & $S V$ & 1 & 0.000523 & 0.000523 & 9.371514 & 7.924503 \\
\hline$B$ & Ton & 2 & 0.005346 & 0.002673 & 47.92032 & 81.04234 \\
\hline$C$ & Toff & 2 & 0.000245 & 0.000122 & 2.194223 & 3.710847 \\
\hline$D$ & \% of $B_{4} C$ & 2 & 0.0000481 & 0.0000241 & 0.431275 & 0.729368 \\
\hline$E$ & Wire feed & 2 & 0.0000421 & 0.0000211 & 0.37749 & 0.638407 \\
\hline$F$ & Wire tension & 2 & 0.0000581 & 0.0000291 & 0.520916 & 0.880968 \\
\hline ERROR & & 6 & 0.000335 & 0.0000558 & 1 & 5.073568 \\
\hline TOTAL & & 17 & 0.006596 & & & 100 \\
\hline
\end{tabular}

From the ANOVA results it is clear that SV and Ton significantly contribute to the MRR and the KW, and that the increase in the MRR is significant as it has a direct influence on the machining cost. It is found that the increase in the MRR is $18 \%$. The contribution of Ton to MRR, SR and KW is significant.

\section{Confirmation test}

The purpose of the conformation test is to validate the predicted results. The confirmation test was carried out by slicing the AMMCs square bar with the combinations A2-B3-C3-D1-E3-F2 presented in the response table. Table14 shows the results of the optimal WEDM process parameters. It is found that the MRR is increased to $40.579 \mathrm{~mm}^{3} / \mathrm{min}$ from $35.759 \mathrm{~mm}^{3} / \mathrm{min}$., SR is decreased to $4.398 \mu \mathrm{m}$ from $4.500 \mu \mathrm{m}$ and $\mathrm{KW}$ is decreased to 367 micron from 371 micron.

Table 14 Results of the confirmation test

\begin{tabular}{|c|c|c|c|c|}
\hline & \multirow{2}{*}{$\begin{array}{c}\text { Initial process } \\
\text { parameters }\end{array}$} & \multicolumn{2}{|c|}{ Optimal process parameters } & \multirow{2}{*}{$\begin{array}{c}\text { Improvement in } \\
\text { percentage }\end{array}$} \\
\hline & & Prediction & Experiment & \\
\hline Level & $A_{1} B_{3} C_{3} D_{1} E_{3} F_{2}$ & $A_{2} B_{3} C_{3} D_{2} E_{1} F_{2}$ & $A_{2} B_{3} C_{3} D_{1} E_{3} F_{2}$ & \\
\hline$M R R / \mathrm{mm}^{3} / \mathrm{min}$ & 35.759 & 40.579 & 42.229 & 18 \\
\hline$S R / \mu \mathrm{m}$ & 4.500 & 4.398 & 4.382 & 2.62 \\
\hline$K W / \mathrm{mm}$ & 0.371 & 0.367 & 0.364 & 1.9 \\
\hline Grey relational grade & 0.91358 & 0.91563 & 0.91704 & \\
\hline \multicolumn{5}{|c|}{$\begin{array}{l}\text { The grey relational grade of prediction improved by an increment of } 0.00205 \text { in comparison with } \\
\text { initial process parameters. }\end{array}$} \\
\hline \multicolumn{5}{|c|}{$\begin{array}{l}\text { The grey relational grade of experiment improved by an increment of } 0.00346 \text { in comparison with } \\
\text { initial process parameters. }\end{array}$} \\
\hline
\end{tabular}




\section{Results and discussion}

AMMCs were obtained from the base metal Al6063 reinforced with boron carbide in three different percentages by using the stir casting method. Experiments were conducted and the optimal process parameters were found to be as follows: servo voltage $26 \mathrm{~V}$, pulse on time $122 \mu \mathrm{s}$, pulse off time $52 \mu \mathrm{s}, \mathrm{B}_{4} \mathrm{C} 6 \%$, wire feed $3 \mathrm{~m} / \mathrm{min}$, and wire tension $49.05 \mathrm{~N}$. The Grey-based Taguchi method has been applied to choose an optimal parameter combination to attain the performance characteristics of maximum MRR, minimum roughness value, and minimum KW. The optimal process parameters were validated by conducting a confirmation test. An optimal process parameter combination for the maximum MRR was found in the eighteenth experiment to be as follows: SV26V, Ton $122 \mu \mathrm{s},-52 \mu \mathrm{s}$, volume of $\mathrm{B}_{4} \mathrm{C} 6 \%$, wire feed $3 \mathrm{~m} / \mathrm{min}$, and wire tension $49.05 \mathrm{~N}$. The key findings from this study are that the MRR is increased to $42.229 \mathrm{~mm}^{3} / \mathrm{min}$. from $35.759 \mathrm{~mm}^{3} / \mathrm{min}$, the SR is decreased to $4.382 \mu \mathrm{m}$ from $4.500 \mu \mathrm{m}$ and the $\mathrm{KW}$ is decreased to 364 micron from 371 micron. Significant improvement in the MRR (18\%) ensures the minimization of the machining cost of AMMCs in the WEDM. It is established that, Ton has a very high significant contribution in achieving the maximum MRR in the WEDM.

\section{Conclusion}

This paper addresses the fabrication of AMMCs, the influence of the reinforcement material on hardness and the analysis of the effect of WEDM process parameters on the selected performance measures, namely MRR, SR and KW. It has been observed that the hardness of AMMCs improves with an increase in the percentage of $\mathrm{B}_{4} \mathrm{C}$. Among the six process parameters of WEDM, pulse on time has a very high significant contribution to all the three performance values. It is found that servo voltage has significant contributions to MRR and KW. A significant improvement in the MRR (18\%) is obtained with an optimal process parameter combination. The increase in the MRR is crucial as it has a direct influence on the WEDM cost. This study also reveals that improvements in SR and KW are minimal. This study can be extended to an investigation into AMMCs containing other new reinforcement materials.

\section{REFERENCES}

[1] Mohantya, R. M.;Balasubramanian, K.; Seshadrib, S. K.Boron carbide-reinforced alumnium 1100 matrix composites:Fabrication and properties, Materials Science and Engineering, A 498 2008, pp.42-52. https://doi.org/10.1016/j.msea.2007.11.154

[2] Mohammad Sharifi, E.;Karimzadeh, F.;Enayati, M. H. Fabrication and evaluation of mechanical and tribological properties of boron carbide reinforced Aluminium matrix nano composites, Materials and Design 32 2011, pp.3263-3271. https://doi.org/10.1016/j.matdes.2011.02.033

[3] Rana, R. S.; Rajesh Purohit; Swadesh singh;SaraswatiRanad; Amit suhane, Synthesis \& Analysis Of Mechanical Properties Of LM24/ B 4 C Particulate Composites, Materials Today, Proceedings 5, 2018, PP. 6038-6044. https://doi.org/10.1016/j.matpr.2017.12.208

[4] FatihToptan;AyferKilicarslan; Ahmet Karaaslan; Mustafa Cigdem; Isil Kerti, Processing and microstructural characterisation of AA 1070 and AA 6063 matrix $\mathrm{B}_{4} \mathrm{Cp}$ reinforced composites, Materials and Design 31, 2010, pp.S87-S91. https://doi.org/10.1016/j.matdes.2009.11.064

[5] Gowri Shankar, M. C;ManjunathShettarb; Sharma, S. S.;AchuthaKinia and Jayashree, Enhancement in Hardness and Influence of Artificial Aging on Stir Cast Al6061- $\mathrm{B}_{4} \mathrm{C}$ and Al6061-SiC Composites, Materials Today, Proceedings 5, 2018, pp.2435-2443. https://doi.org/10.1016/j.matpr.2017.11.023

[6] Kalaiselvan, K.;Murugan, N.; Siva Parameswaran, Production and characterization of AA6061- B 4 C stir cast composite, Materials and Design 32, 2011, pp.4004-4009. https://doi.org/10.1016/j.matdes.2011.03.018

[7] Rama Rao, S.;Padmanabhan, G. Fabrication and mechanical properties of aluminium-boron carbide composites, International Journal of Materials and Biomaterials Applications, 2012, pp.15-18. 
[8] Vijayaraghavan, K.; Arul Kumar, A.; Amos Robert Jayachandran, J.;Subramani, N. Analysis on Aluminium Metal Matrix Composites with Boron Carbide and Graphite, International Journal of Innovative Research in Science, Engineering and Technology, Vol.5, Special Issue 4, March 2016,pp.46-51.

[9] Nisha, M.; Krishnan;Keerthana, BVS. Optimization and Characterization of $\mathrm{B}_{4} \mathrm{C}$ Particle Reinforced AA 6063 Matrix Composites, International Journal and Magazine of Engineering Technology, Management and Research, Vol.4 2017, Issue No6, pp.412-421.

[10] Padmavathy, S.;Sharmila Devi G.;Keerthivasan, T.;Balamurugan, R. Microstructure analysis and mechanical behaviors of Al6063 reinforced with $\mathrm{B}_{4} \mathrm{C}$ and red soil metal matrix composite, Journal of Chemical and Pharmaceutical Sciences, JCHPS Special Issue 3, February 2017, pp.126-130.

[11] Chockalingam, K.;Jawahar, N.;Jeyaraj, K. L.;Kesavasubramanian, C.;Bharathwaj, R. G. Optimisation of $\mathrm{CNC}$ wire EDM process parameters and establishment polynomial process model for multiple performance characterestics, Elixir Mech. Engg. 50 2012, PP.10420-10433.

[12] Nihat Tosun; Can Cogun; Gul Tosun, A study on kerf and material removal rate in wire electrical discharge machining based on Taguchi method, Journal of Materials Processing Technology 152, 2004, pp.316-322. https://doi.org/10.1016/j.jmatprotec.2004.04.373

[13] Snehaa, P.;Mahamani; Ismail;Kakaravada, Optimization of Wire Electric Discharge Machining Parameters in Machining of Ti-6Al-4V Alloy, Materials Today: Proceedings 5, 2018, pp.6722-6727. https://doi.org/10.1016/j.matpr.2017.11.330

[14] Udaya Prakash, J.;Ananth, S.;Sivakumar, G.;Moorthy, T. V. Multi-Objective Optimization of Wear Parameters for Aluminium Matrix Composites $\left(413 / \mathrm{B}_{4} \mathrm{C}\right)$ using Grey Relational Analysis, Materials Today, Proceedings 5, 2018, pp.7207-7216. https://doi.org/10.1016/j.matpr.2017.11.387

[15] Mouralovaa, K.;Kovara, J.;Klakurkovab, L.;Bednara, J.;Benesc, L.;Zahradnicekd, R. Analysis of surface morphology and topography of pure aluminium machined using WEDM, Measurement 114, 2018, pp.169-176. https://doi.org/10.1016/j.measurement.2017.09.040

[16] Ramesh, G.;Uvarajab, V. C.;Sampathkumar, M. S. Influence of process parameters in machining the Hybrid Aluminium metal matrix composites in wire cut EDM-An Experimental investigation, International Research Journal of Engineering and Technology, Volume 03, Issue 01, 2016, pp.219-237.

[17] Shyam Lal;Sudhir Kumar; ZA Khan; AN Siddiquee, Multi-response optimization of wire electrical discharge machining process parameters for A17075/A12O3/SiC hybrid composite using Taguchi-based grey relational analysis, Journal of Engineering Manufacture, 2014, pp. 1-4. https://doi.org/10.1177/0954405414526382

Submitted: $\quad 07.12 .2018$

Accepted: $\quad$ 26.7.2019
Navakodi Gurusamy

Mechanical Engineering Department Thiagarajar College of Engineering Madurai, Tamilnadu, India. navakodig@gmail.com Jawahar Natarajan Ramco Institute of Technology Virudhunagar, Tamilnadu, India. jawahartce@yahoo.co.uk Palaniappan Kanagasabai Palaniappan Mechanical Engineering Department Thiagarajar College of Engineering Madurai, Tamilnadu, India. pazhantce@gmail.com 